\title{
MACROALGAE Fucus vesiculosus OIL: BIODIESEL PRODUCTION USING ALKALINE TRANSESTERIFICATION
}

\author{
Bruno Roberto Petrya, Rafael Cardoso Rial ${ }^{\mathrm{b}, *,}$, Osmar Nunes de Freitas ${ }^{\mathrm{a}}$, Joyce Mara dos Santos Barbosa ${ }^{\mathrm{a}}$, Leandro \\ Fontoura Cavalheiro a , Carlos Eduardo Domingues Nazário ${ }^{\mathrm{a}}$ and Luíz Henrique Viana ${ }^{\mathrm{a}}$ \\ anstituto de Química, Universidade Federal de Mato Grosso do Sul, 79070-900 Campo Grande - MS, Brasil \\ 'Instituto Federal de Mato Grosso do Sul, 79750-000 Nova Andradina - MS, Brasil
}

Recebido em 31/08/2020; aceito em 01/12/2020; publicado na web em 20/01/2021

\begin{abstract}
This work studied the obtaining of methyl biodiesel and ethyl biodiesel using alkaline transesterification from macroalgae Fucus vesiculosos oil (FVO). FVO has $86.59 \%$ of its composition in unsaturated fatty acids, with a greater quantity of linoleic acid and oleic acid, a chemical composition near the soybean oil, the most used raw material for the production of biodiesel. Linoleic acid $(47.88 \%)$, and oleic acid (34.66\%) are the fatty acids present in the greatest amount in FVO, and unsaturated fatty acids correspond to $86.59 \%$ the composition of FVO, a composition of fatty acids close to that of soybean oil, which is the oil most produced and used for the production of biodiesel. To obtain methyl biodiesel (MBFVO) and ethyl biodiesel (EBFVO) the molar ratio oil: alcohol 1: 3 and $1 \%$ alkaline catalyst, $\mathrm{NaOH}$, was used. The yield of the transesterification reaction was evaluated by varying the reaction time between 30 and 60 minutes and the highest yields were obtained after 60 minutes of reaction. In order to check the quality of the obtained biodiesel, the properties acidity index, iodine value, water content, specific mass at $20{ }^{\circ} \mathrm{C}$, oxidative stability, cold filter plugging point and kinematic viscosity were evaluated. The oxidative stability had an induction period below the recommended, but it can be corrected with the addition of antioxidants to the biodiesel. All other physical and chemical properties had values within the stipulated by the regulatory agencies, indicating that the macroalgae Fucus vesiculosus can be a raw material in potential for production of biodiesel.
\end{abstract}

Keywords: Fucus vesiculosus oil; macroalgae; methyl biodiesel; ethyl biodiesel.

\section{INTRODUCTION}

The environmental and energy problems resulting from the indiscriminate use of fossil fuels have motivated the work of several researchers in different parts of the world. The search for alternative forms of energy with the objective of replacing oil and its derivatives totally or partially is still a major challenge, always motivated to achieve energy efficiency combined with a lower emission of pollutants. The petrochemical sector is responsible for major environmental damage. The extraction, transportation and industrial processes of transformation of oil are responsible for spills of crude oil, for the generation of residues and toxic effluents of difficult degradability and for the contamination of underground water reserves. The most aggravating factor is the burning of fuels derived from oil, which results in the production and accumulation of carbon in the atmosphere, contributing directly to the greenhouse effect. ${ }^{1-3}$

Energy from biomass is seen as an option in the search for new renewable energy sources, with emphasis on biodiesel. The use of biodiesel as a fuel has been growing rapidly worldwide, as the production chain of this fuel has promising potential in several sectors, such as social, environmental and technological. ${ }^{4}$

Biodiesel is often obtained through the transesterification reaction. In this reaction, vegetable oils or animal fats react with an alcohol in the presence of a catalyst (acid, basic or enzymatic), producing the corresponding alkyl esters of alcohol and glycerin. There is a wide variety of raw materials and include most vegetable oils such as that obtained from soybeans that participate with more than $70 \%$ of the lipid raw material for biodiesel production in Brazil, in addition to cotton, palm, peanuts, rapeseed, sunflower, saffron, coconut, as well as waste oils and animal fats. ${ }^{5}$ Methanol and ethanol are also the most used alcohols in the production of this biofuel, and

*e-mail: rafael.rial@ifms.edu.br are chosen for the production of biodiesel taking into account the advantages and disadvantages. ${ }^{5,6}$ The most commonly used catalysts for the reaction are alkali metal hydroxides, such as sodium hydroxide $(\mathrm{NaOH})$ or potassium $(\mathrm{KOH})$. The advantages are its high catalytic activity, kinetics and favorable reaction conditions. ${ }^{7-9}$

However, some problems have been reported regarding the use of oilseed sources for the synthesis of biodiesel and one of these problems is the use of the soil for the oilseed agribusiness. ${ }^{10}$ Due to the competition in the use of arable land to produce food and raw material to obtain biodiesel, the use of oils extracted from algae is indicated as an alternative. ${ }^{10,11}$ Algae can be divided into microalgae and macroalgae and both are studied for sources of biofuels. Some review papers reporting the production of biodiesel and other biofuels using macro algae as a raw material are available. ${ }^{11-15}$ Fucus vesiculosus is a brown macroalgae, varying in color between olive green and brown green and reddish brown and grows in a wide variety of coastal areas exposed in saline lagoons and is easily found on sheltered coastal beaches. ${ }^{16}$ Currently, few studies are available in the literature on the use of macroalgae of the genus Fucus in the production of biodiesel. ${ }^{13,17}$

In this context, the main objective of this work was to produce ethyl biodiesel and methyl biodiesel using the alkaline transesterification of the macroalgae Fucus vesiculosus oil, to verify if their physicalchemical properties meet the standards of the regulatory agencies of this sector and show that the biodiesel produced at macroalgae is an alternative that can be an alternative source of renewable energy for the production of biodiesel.

\section{EXPERIMENTAL}

\section{Obtaining and composition of Fucus vesiculosus oil}

Fucus vesiculosus oil (1 liter) was purchased commercially with a guarantee certificate and extracted by mechanical pressing. To identify 
the fatty acid composition present in the oil, the esterification oil was performed as described by Maia \& Rodriguez-Amaya, ${ }^{18}$ and gas chromatography with flame ionization detector (GC-FID) was used. The chromatograph used was the Shimadzu model GC 2010 the BPX column - 70\% Cyanopropyl Polysilphenylene - Siloxane 25 m - 0; $25 \mu \mathrm{m}$ of film, $0 ; 32 \mathrm{~mm}$ of internal diameter. The column temperature ramp during the analyzes was $80^{\circ} \mathrm{C}$, remaining for $3 \mathrm{~min}$. Then it increased at a rate of $10{ }^{\circ} \mathrm{C} \mathrm{min}-1$ until it reached $140{ }^{\circ} \mathrm{C}$ and then continues to increase until a rate of $5^{\circ} \mathrm{C} \mathrm{min}-1$ until it reached $240{ }^{\circ} \mathrm{C}$ where it remained for $5 \mathrm{~min}$. The injector temperature of $250{ }^{\circ} \mathrm{C}$, split ratio $50: 1$ and detector temperature $250{ }^{\circ} \mathrm{C}$. The carrier gas was helium and the injection volume equal to $1 \mu \mathrm{L}$. Fatty acid esters were identified by comparison with the retention times of the fatty acid standard of methyl esters, Mix C4-C24 from Supelco. Quantification was performed by normalization.

\section{Obtaining ethyl biodiesels and methyl biodiesel from Fucus vesiculosus oil}

Fucus vesiculosus oil (FVO) was used as raw material to obtain ethyl biodiesel (EBFVO) and methyl biodiesel (MBFVO). The molar ratio was oil: alcohol was $1: 3$ and $1 \%$ sodium hydroxide $(\mathrm{NaOH})$ was used as catalyst. Initially, the amount of catalyst was previously dissolved in the corresponding alcohol, and after total dissolution in $\mathrm{NaOH}, \mathrm{FVO}$ was added to the reaction medium, at $50{ }^{\circ} \mathrm{C}$, with stirring. After the total addition of the oil, the counting of the reaction time began. The reaction was evaluated in 30 and 60 minutes. Then, the products were transferred to a separating funnel and $10 \mathrm{~mL}$ of water was added to help separate biodiesel: glycerin. After standing for 24 hours, the biodiesel was separated from the glycerin, washed with water, and dried with magnesium sulfate. EBFVO and MBFVO obtained were characterized using the Hydrogen Nuclear Magnetic Resonance spectroscopy $\left({ }^{1} \mathrm{H}\right.$ NMR). The ${ }^{1} \mathrm{H}$ NMR spectra were obtained in a 7.05 Tesla Bruker equipment, model DPX300 (300.13MHz for hydrogen frequency), using $\mathrm{CDCl}_{3}$ as a deuterated solvent. For comparison, ${ }^{1} \mathrm{H}$ NMR spectra of $\mathrm{FVO}$ was also obtained.

\section{Physico-chemical characterization of ethyl biodiesel and methyl biodiesel obtained from Fucus vesiculosus oil}

The physical-chemical properties of EBFVO and MBFVO were made using the methodologies: acidity index (EN 14104), iodine value (EN 14111), water content (ASTM D6304), specific mass at $20{ }^{\circ} \mathrm{C}$ (ASTM D4052), oxidative stability (EN 14112), cold filter plugging point (ASTM D6371) and kinematic viscosity (ASTM D6751).

\section{RESULTS AND DISCUSSIONS}

\section{Chemical composition Fucus vesiculosus oil}

The chromatogram of the fatty acid composition present in Fucus vesiculosus oil (FVO) as a function of the retention time versus the resulting peak intensity is shown in Figure 1.

As shown in Figure 1, the most fatty acid is linoleic acid (C18:2 - 47.88\%), followed by oleic acid (C18:1 - 34.66\%), both unsaturated fatty acids. Table 1 shows the percentage of fatty acid present in the FVO. To compare, the fatty acids of Fucus vesiculosus oil evaluated in other work and soybean oil and beef tallow, which are the raw materials most used to produce biodiesel in Brazil. ${ }^{19,20}$ The amount of FVO fatty acids when compared to that of the literature showed variation in the amount of saturated and unsaturated fatty acids. This variation can be justified by nitrogen depletion is an important factor to increase the amount of fatty acids for the production of biodiesel. ${ }^{21-24}$ The amount of unsaturated fatty acids was close to the amount of unsaturated fatty acids in soybean oil and this high amount of unsaturated fatty acids influences the physicochemical properties of biodiesel. ${ }^{20}$

Obtaining and spectroscopic characterization of ethyl biodiesel and methyl biodiesel from Fucus vesiculosus oil

The EBFVO and MBFVO were obtained in a 1:3 (n:n) molar ratio with $1 \%$ catalyst $(\mathrm{NaOH})$. The conversion yield of $\mathrm{FVO}$ into ethyl biodiesel or methyl biodiesel was evaluated with reaction times of 30 or 60 minutes. The yield of methyl biodiesel after 30 minutes of reaction was $95.5 \%$ and after 60 minutes of reaction it presented $98.8 \%$. For ethyl biodiesel, after 30 minutes of reaction, $94.5 \%$ yield was reached and after 60 minutes, 99.6\%. In Brazil, The National Petroleum, Natural Gas and Biofuel Agency - ANP - recommends in its Technical Regulation $\mathrm{n}^{\circ}$. 45/2014 that biodiesel must have $96.5 \%$ conversion of the raw material into biodiesel. Thus, the recommended reaction time to obtain EBFVO or MBFVO from FVO is then 60

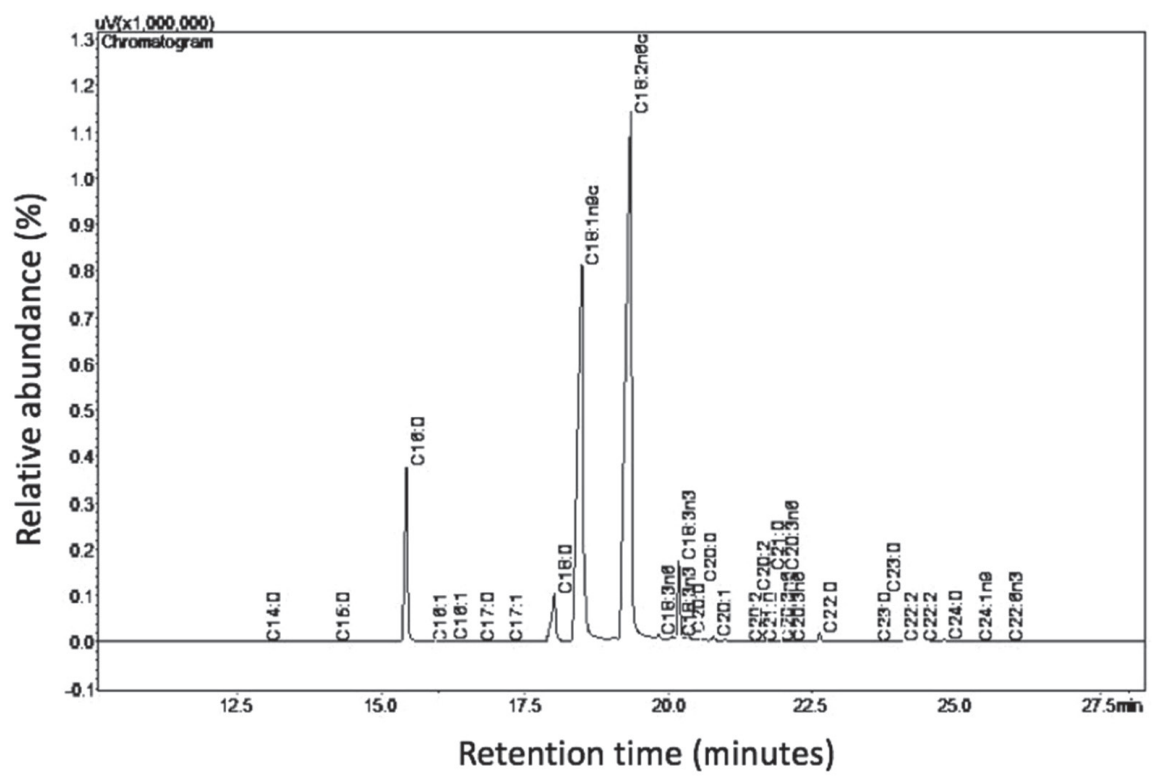

Figure 1. Fatty acids of Fucus vesiculosus oil (FVO) 
Table 1. Percentage of fatty acids present in Fucus vesiculosus oil (FVO) and compared to soybean oil and beef tallow

\begin{tabular}{ccccc}
\hline Fatty Acid & FVO & F. vesiculosus ${ }^{19}$ & Soybean oil $^{20}$ & Beef tallow $^{20}$ \\
\hline C14:0 & 0.06 & 5.60 & 0.12 & 5.13 \\
C15:0 & - & - & - & 1.20 \\
C16:0 & 8.73 & 15.40 & - & 25.04 \\
C16:1 & 0.06 & 1.60 & 3.15 & 3.08 \\
C17:0 & & - & 26.65 & 22.76 \\
C18:0 & 3.61 & 1.40 & 51.76 & 34.51 \\
C18:1 & 34.66 & 18.60 & 5.59 & 2.60 \\
C18:2 & 47.88 & 16.70 & 0.80 & - \\
C18:3 & 3.58 & 5.00 & - & 1.37 \\
C20:0 & 0.66 & - & 15.98 & - \\
C20:1 & 0.41 & - & 26.65 & 58.58 \\
Saturated fatty acids & 13.06 & 22.40 & 57.35 & 38.33 \\
Monounsaturated Fatty acids & 35.13 & 20.20 & 84.00 & 2.60 \\
Polyunsaturated fatty acids & 51.46 & 21.70 & 99.98 & 40.93 \\
Unsaturated fatty acids & 86.59 & 41.90 & 64.30 & 99.51 \\
\hline Total fatty acids & 99.65 & & & \\
\hline
\end{tabular}

minutes, since with 30 minutes of reaction, both biodiesels had conversion rates below the minimum stipulated by the ANP.

After the reaction, aliquots of ethyl biodiesel (EBFVO) and methyl biodiesel (MBFVO) obtained from the FVO were sent to obtain the Nuclear Magnetic Resonance spectra of Hydrogen - ${ }^{1} \mathrm{H}$ NMR. For comparison purposes, FVO spectrum was also obtained. Analyzing the ${ }^{1} \mathrm{H}$ NMR spectra of EBFVO (Figure 2) and the MBFVO spectrum (Figure 3), it is possible to analyze the formation of biodiesels and confirm their purity in relation to the FVO spectrum (Figure 4).

In the ${ }^{1} \mathrm{H}$ NMR spectrum of FVO (Figure 4) there is a multiplet at $4.0 \mathrm{ppm}-4.1 \mathrm{ppm}$ for glycids, a singlet at $2.6 \mathrm{ppm}$ for hydrogen from the methylene group adjacent to carbonyl and the signs at region of 2.0 to $1.0 \mathrm{ppm}$ refer to the methylene hydrogen groups in the chain. In the spectra of the biodiesels obtained from the FVO it can be seen that the transesterification reaction occurred completely because there is a total disappearance of the signals referring to glycerides in the region of $4.0 \mathrm{ppm}$ of the FVO. The absence of signs referring to glycerides and the appearance of a quartet between $4.00-4.03 \mathrm{ppm}$ referring to the methyl hydrogens of ethoxyl in the EBFVO spectrum (Figure 2) and the appearance of a singlet at $3.6 \mathrm{ppm}$ which can be attributed to methyl hydrogens $\left(-\mathrm{O}-\mathrm{CH}_{3}\right)$, in the MBFVO spectrum (Figure 3) indicates the occurrence of the transesterification reaction. Hydrogen Nuclear Magnetic Resonance is a important technique to monitor the formation of biodiesel from oils and fats, in addition to obtaining some physical-chemical properties through the ${ }^{1} \mathrm{H}$ NMR spectra. ${ }^{25-29}$

\section{Physico-chemical characterization of ethyl biodiesel and methyl biodiesel from Fucus vesiculosos oil}

To verify the MBFVO and EBFVO quality, some physicochemical properties were evaluated and the results obtained are shown in Table 2.

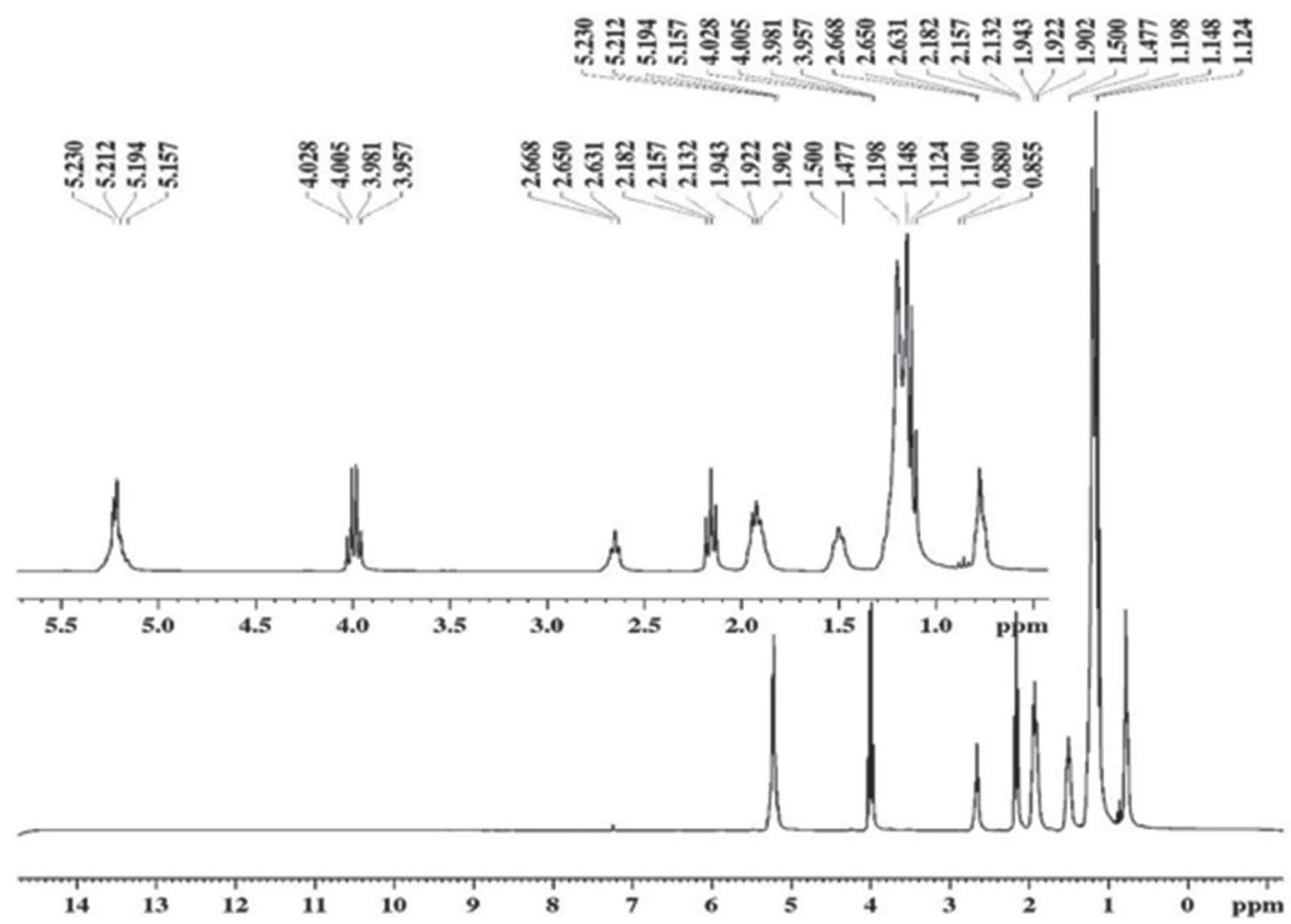

Figure 2. ${ }^{1} \mathrm{H}$-NMR spectrum ( $300 \mathrm{MHz}, \mathrm{CDCl}_{3}$ ) of ethyl biodiesel obtained from Fucus vesiculosus oil (EBFVO) 


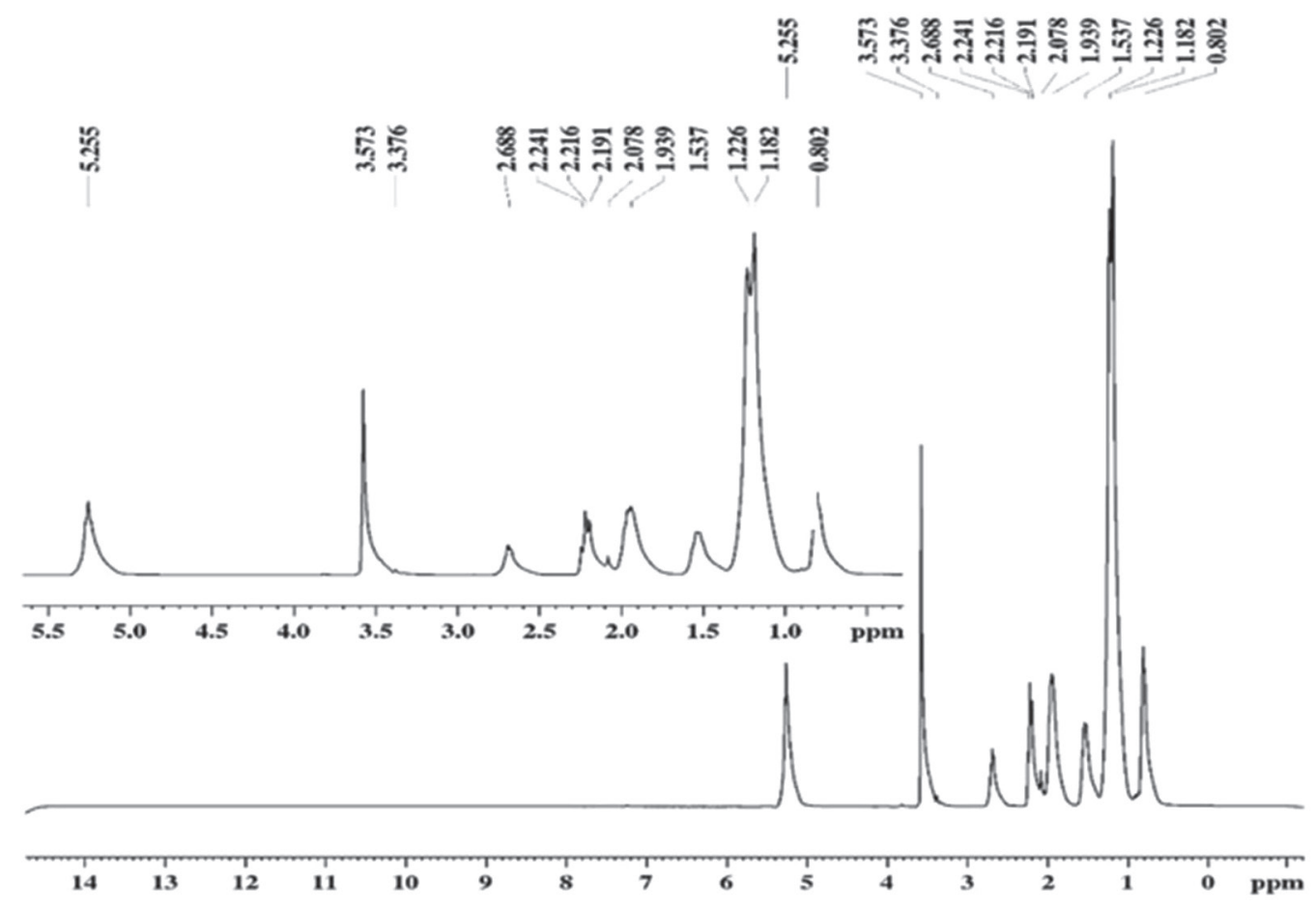

Figure 3. ${ }^{l} \mathrm{H}-\mathrm{NMR}$ spectrum $\left(300 \mathrm{MHz}, \mathrm{CDCl}_{3}\right)$ of methyl biodiesel obtained from Fucus vesiculosus oil (MBFVO)

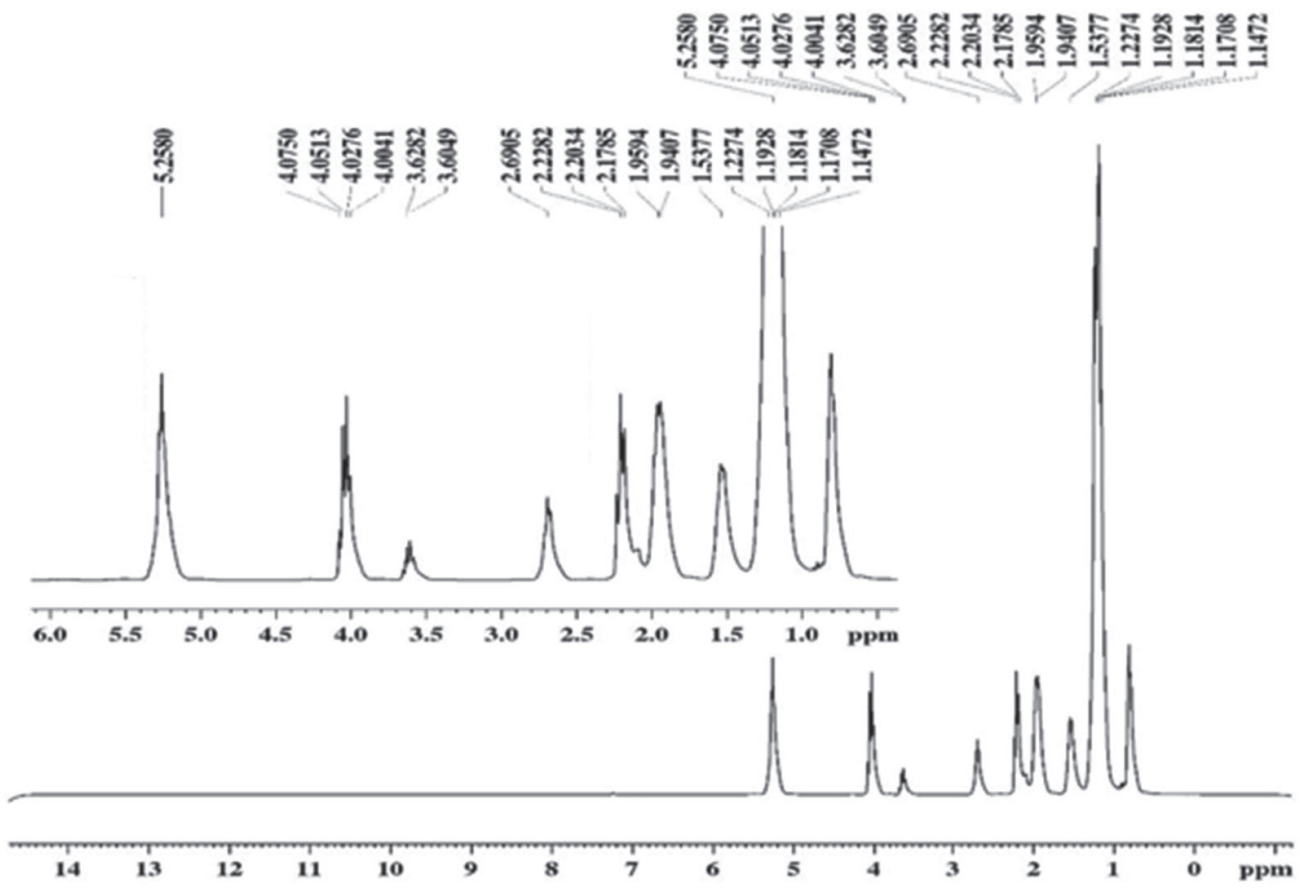

Figure 4. ${ }^{l} \mathrm{H}$-NMR spectrum $\left(300 \mathrm{MHz}, \mathrm{CDCl}_{3}\right.$ ) of Fucus vesiculosus oil (FVO)

The physical- chemical properties of MBFVO and EBFVO have shown that the biodiesels obtained have met most of the quality requirements. The cold filter plugging point presented is a property in which the limits depend on the region in which the biodiesel is sold. Oxidative stability showed a value below that stipulated by EN 14112 , as the standard recommends a minimum induction period of 8 hours and the MBFVO induction period was 4.33 hours and EBFVO induction period was 4.46 hours. This low value for the induction period shows the time in which biodiesel can degrade and this can be explained due to the high amount of unsaturated fatty acids present in the FVO, making them more susceptible to oxidation and degradation reactions. ${ }^{30,31} \mathrm{FVO}$ contains $86.59 \%$ unsaturated fatty acids and these unsaturated fatty acids are in the form of fatty acids methyl esters (FAME) in MBFVO and as fatty acids ethyl esters (FAEE) in EBFVO. On the other hand, oxidative stability can be improved by increasing the induction period with the addition of substances capable of inhibiting or delaying oxidation reactions, called antioxidant substances. In the literature, some studies demonstrate the effectiveness of adding antioxidants to the oxidative stability of biodiesel. ${ }^{32-36}$ The addition of antioxidants in MBFVO and EBFVO can improve the oxidative stability of these biodiesels and thus meet the regulatory standard. The other physico-chemical properties of MBFVO and EBFVO are within the limits stipulated by regulatory standards and this demonstrates that Fucus vesiculosus 
Table 2. Physico-chemical properties of methyl biodiesel (MBFVO) and ethyl biodiesel (EBFVO) obtained from Fucus vesiculosus oil

\begin{tabular}{lccccc}
\hline Property & Unit & MBFVO & EBFVO & Limit & Standart \\
\hline Acidity Index & $\mathrm{mg} \mathrm{KOH} / \mathrm{g}$ & 0.07 & 0.09 & $<0.50$ & EN14104 \\
Iodine value & $\mathrm{g} \mathrm{I} / 100 \mathrm{~g}$ & 111.4 & 108.8 & $<120$ & EN 14111 \\
Water content & $\mathrm{ppm}$ & 73.44 & 105.41 & $<500$ & ASTM D 6304 \\
Specific mass at $20^{\circ} \mathrm{C}$ & $\mathrm{kg} / \mathrm{m}^{3}$ & 881.7 & 871.5 & $850-900$ & ASTM D4052 \\
Oxidative Stability & $\mathrm{hour}$ & $4.33 \mathrm{~h}$ & $4.46 \mathrm{~h}$ & -3 & - \\
Cold filter plugging point & ${ }^{\circ} \mathrm{C}$ & -4 & 4.11 & $1.9-6$ & ASTM D-6371 \\
Kinematic Viscosity & $\mathrm{mm}^{2} / \mathrm{s}$ & 6.44 & & ASTM D6751 \\
\hline
\end{tabular}

oil is an important raw material to be considered for the production of biodiesel.

\section{CONCLUSIONS}

This work evaluated the fatty acid composition of the macroalgae Fucus vesiculosus oil (FVO). The fatty acids present in greater quantities were linoleic acid (C18:2 - 47.88\%), and oleic acid (C18:1 $-34.66 \%)$ and unsaturated fatty acids correspond to $86.59 \%$ of the composition of the FVO and it is similar to the composition fatty acids from soybean oil, which is the most produced and used oil for the production of biodiesel. FVO was used as raw material for the production of methyl biodiesel (MBFVO) and ethyl biodiesel (EBFVO), with molar ratio oil: alcohol 1:3 and $1 \%$ alkaline catalyst. Both biodiesels showed higher yield with a reaction time of 60 minutes. The physico-chemical properties were evaluated and the oxidative stability showed an induction period below the recommended value, but this property can be improved with the addition of an antioxidant substance to biodiesel. The other physical-chemical properties showed values within the stipulated by the regulatory agencies, showing that the macroalgae Fucus vesiculosus is a potential raw material for biodiesel production.

\section{ACKNOWLEDGMENT}

This study was financed in part by the Coordenação de Aperfeiçoamento de Pessoal de Nível Superior - Brasil (CAPES) Finance Code 001.

\section{REFERENCES}

1. Ayres, R. U.; Walter, J.; Environmental \& Resource Economics 1991, 1, 237.

2. Guseo, R.; Dalla Valle, A.; Guidolin, M.; Technological Forecasting and Social Change 2007, 74, 452.

3. Curtis, F.; Ecological Economics 2009, 69, 427.

4. Suarez, P. A. Z.; Meneghetti, S. M. P.; Quim. Nova 2007, 30, 2068.

5. Marchetti, J. M.; Miguel, V. U.; Errazu, A. F.; Renewable Sustainable Energy Rev. 2007, 11, 1300.

6. Kohlhepp, G.; Estudos Avançados 2010, 223.

7. Leung, D. Y. C.; Wu, X.; Leung, M. K. H.; Appl. Energy 2010, 87, 1083.

8. Abbaszaadeh, A.; Ghobadian, B.; Omidkhah, M. R.; Najafi, G.; Energy Convers. Manage. 2012, 63, 138.

9. Stojković, I. J.; Stamenković, O. S.; Povrenović, D. S.; Veljković, V. B.; Renewable Sustainable Energy Rev. 2014, 32, 1.

10. Ajanovic, A.; Energy 2011, 36, 2070.

11. Ahmad, A. L.; Yasin, N. H. M.; Derek, C. J. C.; Lim, J. K.; Renewable Sustainable Energy Rev. 2011, 15, 584.
12. Razon, L. F.; Tan, R. R; Appl. Energy 2011, 88, 3507.

13. Maceiras, R.; Rodríguez, M.; Cancela, A.; Urréjola, S.; Sánchez, A.; Appl. Energy 2011, 88, 3318.

14. Chen, H.; Zhou, D.; Luo, G.; Zhang, S.; Chen, J.; Renewable Sustainable Energy Rev. 2015, 47, 427.

15. Mahendran, J.; Saravanan, K.; Ragulnath, D.; Mater. Today: Proc. 2019, $21,268$.

16. Knight, M.; Parke, M.; J. Mar. Biol. Assoc. U. K. 1950, 29, 439.

17. Urrejola, S.; Maceiras, R.; Pérez Rial, L.; Cancela, M.; Sanchez Bermudez, A.; Chemical Engineering Transactions 2012, 29, 1153.

18. Maia, E.L.; Rodriguez-Amaya, D. B.; Rev. Inst. Adolfo Lutz 1993, 53, 23.

19. Jones, A. L.; Harwood, J. L.; Phytochemistry 1992, 31, 3397.

20. De Freitas, O. N.; Cardoso Rial, R.; Fontoura Cavalheiro, L.; dos Santos Barbosa, J. M.; Domingues Nazário, C. E.; Viana, L. H.; Ind. Crops Prod. 2019, 140, 111667

21. Li, Y.; Horsman, M.; Wang, B.; Wu, N.; Lan, C. Q; Appl. Microbiol. Biotechnol. 2008, 81, 629.

22. Takagi, M.; Watanabe, K.; Yamaberi, K.; Yoshida, T.; Appl. Microbiol. Biotechnol. 2000, 54, 112.

23. Illman, A.; Scragg, A.; Shales, S.; Enzyme Microb. Technol. 2000, 27, 631.

24. Go, S.; Lee, S. J.; Jeong, G. T.; Kim, S. K; Bioprocess Biosyst. Eng. 2011, 35, 145.

25. Gelbard, G.; Brès, O.; Vargas, R. M.; Vielfaure, F.; Schuchardt, U. F.; J. Am. Oil Chem. Soc. 1995, 72, 1239.

26. Costa Neto, P. R.; Balparda Caro, M. S.; Mazzuco, L. M.; Nascimento, M. G; J. Am. Oil Chem. Soc. 2004, 81, 1111.

27. Satyarthi, J. K.; Srinivas, D.; Ratnasamy, P.; Energy Fuels 2009, 23, 2273.

28. Kouame, S.D. B.; Perez, J.; Eser, S.; Benesi, A.; Fuel Process. Technol. 2012, 97, 60 .

29. Mantovani, A. C. G.; Chendynski, L. T.; Galvan, D.; de Macedo Júnior, F. C.; Borsato, D.; Di Mauro, E.; Fuel 2020, 274.

30. Knothe, G.; Fuel Process. Technol. 2007, 88, 669.

31. Pantoja, S. S.; da Conceição, L. R. V.; da Costa, C. E. F.; Zamian, J. R.; da Rocha Filho, G. N.; Energy Convers. Manage. 2013, 74, 293.

32. Kleinberg, M. N.; Rios, M. A. S.; Buarque, H. L. B.; Parente, M. M. V.; Cavalcante, C. L.; Luna, F. M. T.; Waste Biomass Valorization 2017, 10, 797.

33. Varatharajan, K.; Pushparani, D. S.; Renewable Sustainable Energy Rev. 2018, 82, 2017.

34. Rial, R. C.; de Freitas, O. N.; Santos, G. dos; Nazário, C. E. D.; Viana, L. H.; Renewable Energy 2019, 143, 295.

35. Costa, K. de P.; de Viveiros, B. M.; Schmidt Junior, M. A. S.; Suarez, P. A. Z.; Rezende, M. J. C.; Fuel 2019, 235, 1010.

36. Rial, R. C.; Merlo, T. C.; Michalski Santos, P. H.; Dias Melo, L. F.; Barbosa, R. A.; de Freitas O. N.; Domingues Nazário, C. E.; Viana, L. H.; Renewable Energy 2020, 152, 1079. 